\title{
VIOLIN AND PIANO PIECES BY FATTAKH NAZAROV IN CONCERT PERFORMING AND EDUCATIONAL PEDAGOGICAL PRACTICE
}

\author{
Adilhoca Aziz \\ Bilkent Üniversitesi, Müzik ve Sahne Sanatları Fakültesi, adilhoca.aziz@gmail.com
}

Aziz, Adilhoca "Violin and Piano Pieces by Fattakh Nazarov in Concert-performing and Educational-Pedagogical Practice". idil, 73 (2020 Eylül): s. 1495-1503. doi: 10.7816/idil-09-73-11

\begin{abstract}
This article examines piano accompanied vilion pieces by the honored artist of Uzbekistan and Karakalpakstan, composer, conductor, professor Fattakh Nazarov (1919-1982). He is widely demanded in concert-performing and educational-pedagogical practice. Analyzing the pieces for violin and piano by F. Nazarov, the composer focuses on aspects such as programmaticity, imaginative world, musical language, and means of expressive performing. Based on the composer's editions, proposed solutions help performing musicians to achieve high quality sound embodiment and psychological impact on listeners. In this article, the pieces for violin and piano by F. Nazarov are for the first time studied and previously unexplored aspects of the composer's musical heritage are examined. The results of the analysis of F. Nazarov's violin pieces are of scientific theoretical and practical importance, focused on a wide range of concertperforming and educational pedagogical practice.
\end{abstract}

Keywords: Fattakh Nazarov, violin, piece, miniature, intonation, expressive means, technique, musical form, programmaticity, imaginative world 


\section{Introduction}

F. Nazarov (1919-1982) is an honored artist of Uzbekistan and Karakalpakstan, was a conductor, professor of the Mukhtar Ashrafi Tashkent State Conservatory, and a member of the Union of Composers of Uzbekistan. His violin work is one of the most important components of both his multifaceted creative heritage and the musical culture of Uzbekistan. During the years of his life, the composer has dedicated violin compositions of various genres and forms. F. Nazarov's violin works absorbed the centuries-old traditions of the Uzbek musical culture, reflected the progressive trends in the development of Uzbek composer's creativity in the 20th century, and has retained their high artistic value and demand in the 21 st century.

The purpose of this article is to reveal the essence of F. Nazarov's violin music, to describe its characteristic features, inimitable artistic originality, that has the potential to attract contemporary musicians and listeners.

A composer's creativity, like any other type of creative activity, is always a reflection of their life path, the events of their biography. In this sense, it is a necessity to touch upon his appearance as a whole, especially since his life was rich in events.

F. Nazarov was born on January 1, 1919 in the city of Frunze (now Bishkek), the capital of Kyrgyzstan. Naturally gifted with outstanding musical abilities, he received a broad multidisciplinary musical education. At the M. Ippolitov-Ivanov Music School in Moscow he mastered playing the clarinet and cello [8, p.240], then he studied at the Higher School of Military Conductors. Later on F. Nazarov continued his studies at the Tashkent Conservatory, from which he graduated with a degree in symphonic conducting in the class of Professor Mukhtar Ashrafi and in composition in the class of Professor Georgy Mushel. F. Nazarov made an invaluable contribution to the development of the musical culture of Uzbekistan with his fruitful creative art. The Children's School of Music and Arts No. 23 in Tashkent was named after F. Nazarov [9, p. 161].

The fundamental monograph "Composer Fattakh Nazarov" by Akhmed Jabbarov, published in Tashkent in 2017 [6] is devoted to the life and social activities of the composer and conductor.

F. Nazarov's composer's work covers essentially all genres of musical art. A significant part of his legacy is composed of works intended for the musical education of the younger generation. Musicologists of Uzbekistan A. Jabbarov and T. Solomonova noted: "The composer was constantly striving to enrich his educational repertoire. Works such as Five Pieces for Piano, Sonata for Violin, Concertino for Gijak and Piano, Melody and Dance for Violin (also arranged for Gijak), ten Pieces for Piano and ten Pieces for Violin are popular with young performers. His string quartet also enjoys a considerable success" [7, p.148]. Written with a deep knowledge of child psychology, the skill of composing music, with a great artistic taste, F. Nazarov's instructive works are interesting and attractive not only to children, but also to adults, professional musicians, performers and listeners of various age categories and social strata of society.

All this also applies to F. Nazarov's violin work, which is confirmed by the examination of his pieces for violin and piano, published in Moscow and Tashkent in the 1970s - 1980s. These works have become musical classics of the concert-performing and educational-pedagogical repertoire. Despite their widespread demand in musical practice, they have not yet received coverage in scientific and methodological literature.

F. Nazarov's violin music synthesizes many achievements of great composers, develops expressive techniques, that updates the musical and artistic content of historically established genres and forms. At the center of the content of violin music is a person, with his thoughts, feelings, attitude and world perception. The author's violin works vividly embodied an individual approach to the use of expressive and technical capabilities of the violin, with regards to his musical thinking. The composer deeply grasped the specifics of this instrument, which led to the practical usefulness of his violin compositions in musical and pedagogical practice. The composer's pieces for violin and piano multifacetedly reflected the features of the creative individuality. It is a reflection of a bright national identity and root existence, organically combined with the use of modern composer writing techniques. In this sense, F. Nazarov's violin work contributes to the development of cognitive abilities and enrichment of the artistic thinking of musicians-performers.

\section{Methodology}

In accordance with the set goal, the following methodology are put forward in the work and their solutions are proposed: 
- Characterize the figurative world of the plays;

- Analyze musical expressive means;

- Determine the musical form of each piece;

- Reveal the features of the musical style;

- Based on composer's edition, consider the most frequently used strokes and performing techniques

- Develop a performing concept for each piece;

- Summarize the research results and to note the ideological and artistic significance of the composer's viol in work.

The set goals and objectives of the work are relied on modern research methods adopted in the musicology of the $21^{\text {st }}$ century. A. Novikov and D. Novikov emphasize, "Modern science is guided by three basic principles of cognition: the principle of determinism, the principle of correspondence and the principle of complementarity" [12, p. 66]. These principles, which are of systemic importance, are appropriate in the field of musicology, and in particular in this study. This article develops on the problems using the methodology of structural, holistic analysis and comparative-typology, that identifies the expressive and performing means.

\section{Analysis}

This article expands and studies the performing and pedagogical aspects of six pieces for violin and piano: "Lullaby", "Dance", "Dream", "Humoresque", "Uzbek Scherzo", "Song and Dance". The performer should note and consider that these pieces have programmatic titles that indicate their character and genre archetypes.

\section{Lullaby}

The piece "Lullaby" is a charming lyrical miniature with a volume of 50 measures. The work meets all the conditions and requirements inherent in this genre: the pace of the Andante cantabile, the calm, tuneful character of the violin melody and piano part, the smoothness of movement, the classical harmony of the musical form. At the same time, there are a number of very interesting points in "Lullaby" that need to be paid attention to in the process of studying it.

"Lullaby" is written in a three-part reprise form with an introduction and a coda. The structure of the miniature is characterized by classic clarity:

$\begin{array}{llll}\text { A } & \text { B } & \text { A } & \text { Coda } \\ \text { A-major } & \text { e-minor-h- minor } & \text { A-major } & \text { A- major } \\ 14 \mathrm{~m} & 12 \mathrm{~m} & 14 \mathrm{~m} & 10 \mathrm{~m}\end{array}$

The two-measure piano intro prepares the violinist to start playing the main theme, so it is important for him to hear the rising fourth move in the top voice of the piano part. The tempo and character of the music is set by the pianist-accompanist, and the violinist should organically and naturally join the sound aura, find the correct sound balance of the piano nuance. Attention should be paid to the originality of the composer's presentation of the initial ascending quart intonation. In the piano introduction, the first sound of the ascending fourth falls on the second beat of the measure, while in the violin part it falls on the first beat of the measure: measures 1-6. The ascending quarter move from the $\mathrm{V}$ to the 1 st scale is usually used in the iambic motive, emphasizing the heroic, solemn, inviting character of the music. F. Nazarov uses an ascending quarter move in the violin part in the form of a choreus motive, which allows him to convey the lyrical character of the lullaby melody. It is not by chance that the composer chooses the interval of the ascending pure fourth, since he realizes the most important role of this interval in the development of the violinist's hearing. K. Mostras paid special attention to the work on the intonation of the interval, who emphasized, referring to the school of Leopold Auer: "L. Auer attaches great importance to the passage of quarters and regards as a big gap in learning the fact that usually this interval is not given enough attention "[11, p.33].

The piece "Lullaby" is characterized by a surprising unity of the violin and piano parts. The main performing touch in it is the smooth, flexible legato. All motives and phrases in "Lullaby" should be rounded, syncopated flexible, without sudden jerks and movements, dynamic ups and downs are gradual.

In the middle section of the piece, the performer should feel the mode change. At the same time, the appearance of the minor key and the sound of the main theme in a higher register, an octave higher than in the first section, should be set off with the nuance mf: measures 15-18.

The use of the mf nuance allows the violinist to more naturally approach the forte nuance in the culminating 
phase of musical development: measures 19-22. Here it is advisable to slightly expand the movement of the music and apply a slight vibration. The violinist must listen carefully to the piano part: the wide-spread arpeggiated chords create favorable conditions for the violin melody soaring in the high register.

In the reprise, the original character of the music should be resumed and the piece concludes with a melodious coda: measures 41-45. The dynamic profile of the coda differs in a variety of shades of sound from pp to f and ppp, therefore it requires careful work on these sound gradations, avoiding sharp changes in resonance. Performing intuition and good artistic taste will help violinists find compelling sonic colors. "Lullaby" is very useful for developing the skills of the violin cantilena, of dynamic shades, and the development of modal hearing.

\section{Dance}

The piece "Dance" portrays a picture of an energetic dance movement, in which all participants are involved. Allegro tempo is delicately detailed imitation of repeated swirling dance movements. "Dance" has a three-part reprisal structure. The variational repetition of the material based on figurative and ornamental formulas imitating dance movements plays an important role in the organization of the musical form. In general, the structure of the "Dance", which takes up 90 measures, is schematically represented in the following expression:

$\begin{array}{lll}\text { A } & \text { B } & \text { A } \\ \text { e-minor } & \text { C-major } & \text { e-minor } \\ 1-32 \mathrm{~m} & 33-68 \mathrm{~m} & 69-90 \mathrm{~m}\end{array}$

"Dance" opens with a four-bar piano variation based on the main theme of the play. It is presented in the form of an octave unison, emphasizing the monody nature of oriental dance. The national modal harmony of "Dance" roots from the monody nature of music. The main theme of the play is woven of patterned intricate figurations: measures 5-8. All subsequent melodic formations, embodying imitations of oriental dance movements de velops from the prior volumes. Performing melodic figurations requires the technical skill of the violinist, lightness, flightiness of the playing, avoidance of excessive bow pressure on the string.

The violinist's attention to the quality of sound production increases according to the f nuance and the appearance of chords and double notes: of measures 13-16. These performing means must be meaningful and purposeful to achieve a high artistic result. As O. Shulpyakov emphasizes "Technique is not a set of conditioned-reflex connections (although the latter are included in it at a certain level as necessary components), but a formed performance skill, the basis of which is perfect coordination of movements, which consists in the ability to transmit by means of one's instrument the ideological and figurative content of the embodied work "[14, p.96].

The intense melodic development leads to vibrant dynamic chords in the violin part, while the main theme is in octave unison in the piano part. Playing chords in this section of the piece requires special attention from the violinist: measures 25-28. The ff nuance indicates the need for a surround sound instrument. "The extreme strings provide the necessary sounding force" [4, p.23]. Therefore, the violinist here should use the sonic perspectives of the extreme strings, achieving a light, flighty and at the same time bright, rich timbre color.

In the middle section of the "Dance", the movement of the music acquires a lyrical character, as the tune becomes smooth and songful. Performing this melody requires the use of the legato stroke: measures 33-38. The use of this playing technique allows the violinist to expressively convey the plasticity of the oriental dance. "In the legato stroke, due to the constant change in the pitch of sounds, the point of sound production on the string, even in one nuance, should change" [13, p.35]. In this case, in the nuance of $\mathrm{mf}$, the violinist should take into account the sound production factors of the legato application.

It is important for the violinist to find an artistically convincing solution for the transition from the middle section to the reprise. The beginning of the transition should sound very impressive to create a vivid performing form of the "Dance": measures 69-72.

The sound of the violin in the ff nuance in the high register should be sunny, radiant, illuminating with its bright radiance, delighting listeners with the beauty of the violin tone. In this work, the functions of an abbreviated reprise and a coda are combined. This interpretation by the composer of the musical form is artistically justified, since the dance usually ends with the culmination of the action. In accordance with this, the completion of the "Dance" should be performed very brightly and effectively: in the 86th measure, a nuance pp is required, and the next four measures from the 87th to 90th measures should be played in a dynamic gradation from $\mathrm{f}$ to $\mathrm{ff}$ in synchronous unison violins and piano. 


\section{Dream}

The play "Dream" attracts attention with its romantic imagery. It presents the violinist with the opportunity to express their imagination and creativity in the miniature sound embodiment. The piece is 40 measures long. It is written in a three-part reprisal form and its construction can be schematically expressed in the following form:

$\begin{array}{llll}\text { A } & \text { B } & \text { A } & \text { Coda } \\ \text { g-minor-d-minor } & \text { B-major-d-minor } & \text { g-minor-d-minor } & \text { d-minor } \\ \text { m1-10 } & \text { m11-26 } & \text { m27-34 } & \text { m35-40. }\end{array}$

The play "Dream" is characterized by a pronounced oriental flavor, which is reflected in the natural-modal organization of melody and harmony, rhythm and texture. Throughout the Moderato tempo, there are iambic intonations. These modulating constructions mirror a reflexivity, as if there is continuous transfer of the state of mind. The expressiveness of intonation is especially an important role in the performance of a miniature. I. Lesman noted that "a necessary condition for expressive sound is its high quality, without which it cannot satisfy the listener; any contamination of the sound with certain sounds interferes with the perception of the content of the work " $[10$, p.131]. Benign intonation is the most important factor in achieving the expressiveness in the given play. The violinist must feel the lyrical nature of the melody: measures 2-6.

The opening melody of the piece "Dream" has an original structure, set off by colorful harmony. The piano intro, which prepares the violinist to play his part, creates the feeling of a natural scale in $\mathrm{g}$ minor with echoes in B major in the 6th measure. In the initial melody, there are two elements: song and dance, forming a single unity. To perform the element as a lyrical song, the performer should apply the legato stroke, and to imitate the part as a dance element the performer should apply a dotted rhythm, where it is advisable to use easy detache.

When repeating the melody in the 7th - 10th measures, the performer should achieve even greater penetration of the sound of the instrument, using a small quivering vibration in the performance of the first element of the melody and distinct articulation when playing the second element. Further, the construction ends with a cadence in the main key of the piece in d-minor.

The middle section of the miniature has a laid-back dance character. Its melody grows out of the second element of the initial theme: measures 11-14. The melody is set in high register. It should sound light and sonorous, in the f nuance, and when repeated, it can be played in the mf nuance, creating dynamic contrasts that contribute to the variety of sonic colors of the violin.

The reprise of the play is very original, which is built as a mirror image of the first section. Here, the second structure in high register sounds first, and then the first structure sounds in the middle register. This compositional technique used in F. Nazarov's "Dream" gives the miniature features of a concentric form. The six-bar code complementing the reprise, indicated by the p dolce remark, seems to dispel tender lyrical dreams in the heavenly distant height.

\section{Humoresque}

"Humoresque" is interesting for its bright, nationally distinctive genre flavor. The piece introduces into the atmosphere of a festive cheerful mood, as if there is a circle of cheerful playful images. Brightly national in expressive means, with tart quarter-second harmonies and clear Usul drawings in the piano part, "Humoresque" provides the violinist with a fertile opportunity to demonstrate their performing skills. The total length of the piece is 46 measures. The play has a three-part reprise form with a coda:

$\begin{array}{lll}\text { A } & \text { B } & \text { A } \\ \text { G-major } & \text { e-minor } & \text { G-major G-major } \\ \text { m1-15 } & \text { m16-28 } & \text { m29-40 m41-46. }\end{array}$

In the performance of the first part of the piece, the violinist must pay special attention to the clear articulation of the playing. I. Braudo noted that "the action of articulatory means is often associated with other expressiveness - dynamics, rhythm" [2, p. 17]. In this case, as in measures 4-7, the clear articulation of the violin intonation, which is reflected in the dynamics and rhythmic textures in the piano part, is important in creating a vivid musical image.

The dynamic aspects of the articulation of a given theme, which is repeated in different textural conditions must be creatively interpreted by the performer. This allows the performer each time to bring a new sensation in their intonation.

In the performance of the middle section, the violinist must embody a sound image that contrasts with the music 
of the first movement. The composer used here the principle of contrast at the levels of mode, intonation and rhythmic expressiveness. The major is replaced by a parallel minor. The instrumental, figurative form of the melody gives way to the vocal one; accompanying the violin melody, the piano accompaniment is replaced by the arpeggiated one. These expressive means must be understood by the violinist and reflected in his playing. The character of the music of the middle part of "Humoresque" is determined in the piano part, which prepares the violinist for the performance of their part of the piece. The beginning of the middle part requires the violinist to be able to convey the lyrical character of the music. Its tunefulness, melodic beauty, gracefulness of decorations can be seen in measures 20-23. The development of subtle emotional nuances that will create a lyrical mood can be achieved with the use of the legato stroke in the middle section.

In the reprise, it is necessary to renew the image of the original sound. The next coda Meno mosso completes the integrity of the musical form of this charming piece, in which the composer manages to convey both the humor of the moment and his optimistic perception of the world.

\section{Uzbek Scherzo}

"Uzbek Scherzo" is an intense concert piece that requires a bright temperament and artistry from the violinist. The specificity of this work lies in the exceptional energetic activity of the striking technique of the performer.

The play is characterized by the deep national identity, relying on Uzbek folk dance culture and traditions. The total length of the piece is 105 measures. "Uzbek Scherzo" has a characteristic three-part reprisal form with a coda:

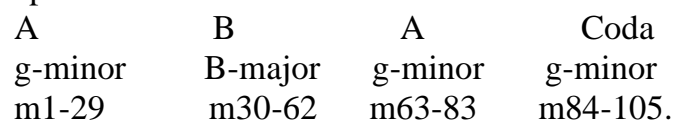

The piece is symphonic in its scale and principles of musical development. It requires from the performer a determined concentration and energy. Boris Gutnikov said in one of his conversations that "if we use the terminology fashionable today then the method of the 'extensive` approach to the upbringing of an instrum entalist has been replaced by 'intensive methods of development" [5, p. 39]. This reasoning of the famous violinist and teacher is of direct importance in the process of mastering the "Uzbek Scherzo". The intensity of the tone of the game should be felt from the very first measure, from the very first sound requiring the sound activity of an energetic downward melodic movement (measures 1-4). In most of F. Nazarov's pieces, piano initiates an introduction that gives an emotional and semantic adjustment of the character of the music. However in "Uzbek Scherzo" the violin takes the lead from the beginning. It is advisable to play the beginning of the piece with a spiccato stroke. As A. Sherinsky notes "the spiccato stroke most often brings sharpness, elasticity of rhythm, is widely used in various genre scherzous episodes" [13, p.44].

The middle part of the "Uzbek Scherzo" contributes to contrast of the musical development of the image. It has an eight-measure piano introduction, thus preparing the violinist for the sound embodiment of a new theme, which has a lyrical song character. This theme, in measures $39-42$, in contrast to the first theme, has a movement in upward direction. It should be performed with a legato stroke, and a gentle melodious sound. In the process of developing this theme, F. Nazarov uses double notes, as in measures 59-60, and it requires a special attention to the intonational side of the performance. When playing double notes, it is advisable to slightly expand the movement, listening attentively to their sound. In the 61 st and 62 nd measures, the performer should slow down the tempo in accordance with the ritenuto indication in the musical text in order to show the beginning of the recapitulation. In the 63rd measure the performer should play more vividly and prominently. The reprise resumes the original tempo and character of the music. The composer did not make any significant changes to the reprise, but he added the expanded coda combining the first and the second themes.

One of the most widely demanded in concert-performing and educational-pedagogical practice is the wonderful composition "Song and Dance". In fact, it is a poetic, colorful sketch of the folk life, a lyric-genre concert poem that organically combines the two most important genres of universal art - song and dance. This work is notable for the composer's deep penetration into the philosophy, aesthetics and psychology of folk life, which determined the high artistic level of the work, its relevance and celebrity not only in Uzbekistan, where it was created but also beyond the boundaries. This work portrayed the artistic and aesthetic principles and reflected the characteristic features of the national inventive inimitable style of the composer. 


\section{Song and Dance}

"Song and Dance" is a three-part reprise composition with a contrasting middle section. The outer sections are based on the song and the middle section is based on the dance. The total volume of the piece is 119 measures. Schematically, the form of the work is as follows:

$\begin{array}{lll}\text { A } & \text { B } & \text { A } \\ \text { e-minor } & \text { C-major } & \text { e-minor } \\ \text { m1-45 } & \text { m46-95 } & \text { m96-119 } \\ \text { song } & \text { dance } & \text { song } \\ \text { Andantino } & \text { Allegro moderato } & \text { Andantino }\end{array}$

The composer constructed the highly valued and demanded work with a mastery of genres and forms of song and dance styles. This work became a classic of the twentieth century, along with the Concerto for Piano and Orchestra, also noted for the mastery of building a cyclic structure. "In the principle of a clear differentiation of the sections of the concert, the composer served to change the texture, section, character of the image, which allows him to master the musical text extremely quickly and realize its drama" [1, p. 66]. The same is observed in "Song and Dance", where the cyclical form of song and dance is clothed in a more complex concert-symphonic structure and at the same time is easily comprehended by both the performer and the listener. This quality has made the "Song and Dance" a sustainable piece of work for various versions of instrumental compositions. "Due to its wide popularity, this work was transcribed by the author (at the request of the department of Uzbek folk instruments) for a gidjak with an orchestra of Uzbek folk instruments and for a violin with a symphony orchestra" [6, p. 223].

The song "Song and Dance" is characterized by a deep inner integrity that has a bright contrast in between its sections. In this sense, this work can be related to the Concerto for Piano and Orchestra. "The first part of the song character, due to the common rhythmic pulsation is perceived by the ear very closely and wholeheartedly. This is facilitated by the skillful use of harmonic means of expressiveness of the texture of the piano accompaniment" [6, p.222-223]. Performed at an Andantino tempo, it is based on the beautiful and at the same time soulful melody. Its smooth progressive movement, light transparent grace notes impart sophistication and elegance to musical development: measures 3-10. The performance of the melody requires from the violinist; a gentle soft sound, a legato stroke, a light quivering vibration. From the 11th measure onwards, the melodic elements of the theme receive ornamental-filigree coloring in the piano part. In the violin part; light, transparent, airy chords ring in the air, played by the pizzicato technique. The main theme is repeated twice, while it is originally enriched with new textured and harmonic colors, leading to a virtuoso cadenza ad Libitum. This cadenza ends with a sustained high-register sound and a fermata, followed by the middle section of the Allegro moderato dance character. Here, there is a change in

the mode, scale and character of the music. A clear percussion-dotted rhythm is present in the size of $\frac{6}{8}$. The violin part is based on the use of chords and double notes, combined with melodic elements as seen in measures 46-51. To convey the dance character of the music in the middle section the violinist needs to master various strokes and the technique of playing double notes.

A seven-measure piano interlude from bars 89 to 95 makes a major transition to the reprise. The original Andantino tempo resumes and the main song melody resounds in measure 97 . The reprise returns the listener back to the initial lyrical mood and ends with a small coda. L. Ginzburg noted that "in the process of working on a work the necessary conditional connections arise between auditory representations and muscular sensations, inducing motor skills" [3, p. 34]. Similarly, this work provides a performer musician with the opportunity to show different sides of his talent and abilities: expressive and technical skills, imaginative thinking, and the ability to create a performing form.

Using various means of violin expressiveness, a musician, in the process of working on a piece, finds exactly those playing techniques that will help him create an individual performing concept.

\section{Conclusion}

Various pieces for violin and piano by F. Nazarov contribute to the enrichment of the musician's performing skills, professional and intellectual creative development. They are extremely useful in many ways and aspects of mastering the musical classics of the 20th century. F. Nazarov's violin works have a classically clear compositional structure, into which he introduced new, original methods of updating the form, content and style, while maintaining both his unique bright individuality and national identity. 
The interpretation of pieces for violin and piano by F. Nazarov poses problems to the performer related to the disclosure of the artistic depth of music, its aesthetic value and technological problems associated with mastering the strokes and techniques of playing. The combination of these coordinates in the process of studying F. Nazarov's violin works will be of great use in mastering the music of other composers of our era.

\section{REFERENCES}

Azizova-Nazarova G. Piano Concerto of Fattakh Nazarov (experience of performing analysis) // Questions of musical art and pedagogy. Issue VIII. - Tashkent, 2014, p. 58-69.

Braudo I. Articulation (On the pronunciation of melodies). - Leningrad, 1973, p198.

Ginzburg L. About work on a piece of music. - Moscow, 1981, p148.

Gurevich L. Violin strokes and fingering as a means of interpretation. - Leningrad, 1988, p112.

Gutnikov B. On the art of violin playing. - Leningrad, 1988, p56.

Jabbarov A. Composer Fattakh Nazarov. - Tashkent, 2017, p260.

Jabbarov A., Solomonova T. Composers and musicologists of Uzbekistan. - Tashkent, 1975, p238.

Zhabborov A. Ozbekiston composerlari, bastakorlari va musiқashunoslari. - Tashkent, 2018, p438.

Composers and musicologists of Uzbekistan. - Tashkent, 2018, p248.

Lesman. Essays on the method of teaching violin playing. - Moscow, 1964, p272.

Mostras K. Intonation on the violin. - Moscow - Leningrad, 1947, p138.

Novikov A., Novikov D. Methodology of scientific research. - Moscow, 2010, p280.

Shirinsky A. Barcode technique of the violinist. - Moscow, 1983, p85.

Shulpyakov O. Movement, skill and exercise in the performing process (problems of methodology) Questions of theory and history of bowed performance. - Leningrad, 1985, p.88-114 


\title{
KONSER VE EĞITIM UYGULAMALARINDA FATTAKH NAZAROV'UN KEMAN VE PIYYANO PARÇALARI
}

\author{
Adilhoca Aziz
}

ÖZ

Bu çalışma, Özbekistan ve Karakalpakstan'ın değerli sanatçısı, besteci, şef, profesör Fattakh Nazarov'un (1919-1982) keman ve piyano parçalarını incelemektedir. Konser performanslarında ve eğitim-pedagojik uygulamalarında talep edilen F. Nazarov, keman ve piyano parçalarında programatiklik, yaratıcı dünya, müzik dili ve etkileyici icra araçları gibi konulara odaklanmaktadır. Bestecinin önerilen çözümleri, müzisyenlerin, dinleyicilerin üzerinde psikolojik etki ve yüksek kaliteli ses şekillenmesi elde etmelerine yardımcı olur. Bu makalede ilk kez F. Nazarov'un piyano eşliğinde keman eserleri incelenmiş ve bestecinin müzik mirasının daha önce keşfedilmemiş yönleri incelenmiştir. F. Nazarov'un keman parçalarının analizinin sonuçları teorik ve pratik öneme sahiptir.

Anahtar Kelimeler: Fattakh Nazarov, keman, parça, minyatür, tonlama, anlatım araçları, teknik, müzikal biçim, programatiklik, yaratıcı dünya 